\title{
WEIGHTED ESTIMATES OF MULTILINEAR FRACTIONAL INTEGRAL OPERATORS FOR RADIAL FUNCTIONS
}

\author{
YASUO KOMORI-FuRUYA AND ENJI SATO
}

Abstract. Moen (2009) proved weighted estimates for multilinear fractional integral operators. We consider weighted estimates of these operators for radial functions and power weights and obtain a better result. Our result is a multilinear variant of the one by De Napoli, Drelichman and Durán (2011). As applications, we get improvements of the bilinear Caffarelli-Kohn-Nirenberg's inequality.

Mathematics subject classification (2010): 42B20.

Keywords and phrases: Multilinear fractional integral operator, radial function, power weight.

\section{REFERENCES}

[1] L. A. Caffarelli, R. Kohn and L. Nirenberg, First order interpolation inequalities with weights, Compositio Math. 53 (3) 259-275 (1984).

[2] P. D' ANCONA AND R. LuCA', Stein-Weiss and Caffarelli-Kohn-Nirenberg inequalities with angular integrability, J. Math. Anal. Appl. 388 (2), 1061-1079 (2012).

[3] P. De NÁPoli, I. Drelichman And R. G. Durán, On weighted inequalities for fractional integrals of radial functions, Ill. J. Math. 55 (2), 575-587 (2011).

[4] P. De NÁpoli, I. Drelichman And R. G. DuRán, Improved Caffarelli-Kohn-Nirenberg and trace inequalities for radial functions, Commun. Pure Appl. Anal. 11 1629-1642 (2012).

[5] J. DuOANDIKOETXEA, Fractional integrals on radial functions with applications to weighted inequalities, Ann. Mat. Pura Appl. 192 (4), 553-568 (2013).

[6] L. Grafakos, Modern Fourier analysis. Second edition. Graduate Texts in Mathematics, 250, $\mathrm{xv}+504$ pp, Springer, New York (2009).

[7] A. Lerner, S. Ombrosi, C. Pérez, R. H. Torres and R. Trujillo-GonzÁlez, New maximal functions and multiple weights for the multilinear Calderón-Zygmund theory, Adv. in Math. 220 (4), 1222-1264 (2009).

[8] K. MoEn, Weighted inequalities for multilinear fractional integral operators, Collect. Math. 60 (2), 213-238 (2009).

[9] K. Moen, Sharp one-weight and two-weight bounds for maximal operators, Studia Math. 194 (2), 163-180 (2009).

[10] E. M. Stein AND G. Weiss, Fractional integrals on n-dimensional Euclidean space, J. Math. Mech. 7, 503-514 (1958).

[11] E. M. STEIN, Singular integrals and differentiability properties of functions, Princeton Mathematical Series, No. 30, xiv+290 pp, Princeton University Press, Princeton, N.J. (1970). 